\title{
Uterine Tachysystole
}

National Cancer Institute

\section{Source}

National Cancer Institute. Uterine Tachysystole. NCI Thesaurus. Code C92911.

Greater than 5 contractions in 10 minutes averaged over a 30 minute window. 